Revista de
Economida
Contemporâned

\title{
A ASCENSÃO DA CHINA, A ÁSIA E O SUL GLOBAL*
}

\begin{abstract}
Ho-fung Hung ${ }^{a}$

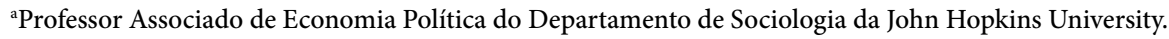

Artigo recebido em 26/06/2017 e aprovado em 20/10/2017

RESUMO: Muitos veem o milagre da economia chinesa como uma ilustração de um modelo de desenvolvimento alternativo à ortodoxia neoliberal promovida por Washington. Também se assume muitas vezes que o envolvimento econômico e político da China nos países do sul global, particularmente nos vizinhos asiáticos, está criando uma nova ordem geopolítica que desafiaria a dominação norte-americana. Neste artigo, argumenta-se que o milagre do desenvolvimento orientado pela exportação nada mais é do que uma parte constitutiva da ordem neoliberal, e que o crescimento da China como exportadora de capital segue os passos de outros poderes capitalista-imperialista se seus projetos de influência política no exterior. Isso tem gerado apreensão crescente entre os países vizinhos em relação à dominação regional chinesa e colocado a China em rota de colisão com os Estados Unidos, que ainda dominam a ordem política e de segurança na Ásia-Pacífico, precipitando uma nova competição entre potências imperiais.
\end{abstract}

PALAVRAS-CHAVE: China; Âsia; sul global; ordem global neoliberal.

CLASSIFICAÇÃO JEL: O10; O53; P16.

* Tradução: Hugo Dahlin e João Victor Guimarães

Correspondência para: Ho-fung Hung

Contato: hofung@jhu.edu 


\title{
RISING CHINA, ASIA, AND THE GLOBAL SOUTH
}

\begin{abstract}
Many see the Chinese economic miracle as an illustration of an alternative model of development to the neoliberal orthodoxy promoted by Washington. It is also assumed that China's increasing economic and political involvement in the Global South, particularly in its neighboring countries in Asia, is creating a new geopolitical order challenging American domination. In this paper, I argue that China's exportoriented developmental miracle is in fact a constitutive part of the global neoliberal order, and that China's rise as a capital exporter is making it follow the footstep of preceding capitalist-imperialist powers to project its political influence overseas. This creates increasing anxiety among Chinese neighbors about a Chinese regional domination. It also puts China onto a course of collision with the US, which still dominates existing political-security order in the Asia-Pacific, precipitating a new inter-imperial competition.
\end{abstract}

KEYWORDS: China; Asia; global south; neoliberal global order. 


\section{INTRODUÇÃO}

O boom econômico da China nas três últimas décadas, apesar de estar perdendo fôlego nos últimos anos, tem fascinado muitos e provocado uma gama extensa de reflexões sobre como uma potência econômica está dando novas formas aos modelos de desenvolvimento de outras economias do sul global. Há variadas análises que buscam retratar o crescimento chinês como uma antítese ao Consenso de Washington, e muitos veem a China como um exemplo de modelo de desenvolvimento alternativo que poderia ser replicado em outros países em desenvolvimento. Ao mesmo tempo, muitos preveem que a China irá desafiar a dominação geopolítica dos Estados Unidos e criar uma nova ordem política na Ásia e até mesmo no mundo.

Neste artigo, meu argumento é que o boom da economia chinesa se origina na convergência dos legados de dois lados da Guerra Fria: do desenvolvimento maoísta e do modelo de desenvolvimento orientado para as exportações do leste asiático. É uma condição única que dificilmente pode ser replicada em outros países em desenvolvimento. Mais ainda, a fonte final do dinamismo da economia chinesa vem do seu setor exportador, que tem sido dominado por empresas privadas (nacionais ou estrangeiras) e muito bem integradas no circuito global de livre comércio. É nesse mesmo setor exportador que a expansão de empresas estatais relativamente não lucrativas tem se baseado. Nesse sentido, o boom da China só é possível pela participação do país na ordem global neoliberal caracterizada pelo livre comércio e livre mobilidade de capital, estando, portanto, longe de ser um rompimento com essa ordem.

Enquanto o boom chinês foi criado sob circunstâncias histórico-globais e de trajetórias de desenvolvimento muito específicas, que não podem ser copiadas facilmente, esse crescimento criou impactos contraditórios nos países vizinhos e em outros países em desenvolvimento fora da Ásia. De um lado, o crescimento gera uma pressão intensa por competitividade nos outros países exportadores de manufaturas intensivas em trabalho, levando-os a adotar e a se conectar às cadeias de produção e de commodity sinocêntricas. Por outro lado, esse crescimento também fomenta um boom de commodities nos países agroexportadores. Geopoliticamente, o crescimento da participação econômica da China no sul global está pressionando Pequim a iniciar sua projeção de poder político e militar no exterior, o que tem criado um contramovimento nos países vizinhos e em outros países em desenvolvimento, levando-os a alianças mais estreitas com os Estados Unidos. Dessa forma, o boom chinês está criando impactos variados na perspectiva de desenvolvimento dos países do sul ao mesmo tempo em que promove a rivalidade interimperial entre a China, com poder geopolítico crescente, e os poderes ocidentais já estabelecidos, especialmente os Estados Unidos. A ascensão da China não cria uma nova ordem político-econômica, como muitos esperam, mas faz a ordem atual mais fragmentada. 


\section{DO BOOM DA CHINA À CRISE DE SUPERACUMULAÇÃO}

De modo resumido, o boom chinês é a culminação da solução encontrada pelos Estados Unidos e por outros países centrais frente à crise econômica da década de 1970 . Começando pelo final da década de 1960, a taxa de lucro em setores manufatureiros nos países centrais caiu, enquanto o capital teve de ceder espaço às demandas crescentes da militância trabalhista. Europa e Japão, recuperados da carnificina da Segunda Guerra Mundial, desenvolveram regimes eficientes de manufatura que mais à frente criaram tensões que afetaram a lucratividade do mencionado setor nesses países e nos Estados Unidos. Foi na década de 1970 que a terceirização da produção manufatureira dos países centrais para as economias com baixos salários no leste asiático - Coreia do Sul, Taiwan, Hong Kong e Cingapura, seguidos depois por outros, como Malásia e Tailândia - surgiu como solução para aumentar o lucro das corporações do centro. Essa "hemorragia de trabalho" no setor manufatureiro se acelerou depois da promoção do livre comércio pela administração Reagan. A desindustrialização do norte global tirou poder de barganha da força de trabalho organizada e fez com que reformas neoliberais anti-trabalhistas surgissem - incluindo desregulamentação dos mercados e privatização, compressão do Estado de bem-estar social, desregulamentação da relação capitaltrabalho etc. - nos países centrais onde isso foi politicamente possível.

Contudo, a oferta de trabalho barato de origem rural nas economias asiáticas convergentes aos Estados Unidos durante a Guerra Fria era fraca. Foi justamente no início dos anos 1990, quando essas economias atingiram níveis de renda média ou até mesmo de renda alta em relação à hierarquia global por conta dos seus salários em alta, que as reformas de mercado chinesas ganharam uma orientação exportadora. As reformas, que começaram já em 1978, reviveram o empresariado rural como resposta ao estancamento da acumulação primitiva socialista, mas encontraram graves crises no final dos anos 1980 e começo dos 1990, marcadas por hiperinflações e deficit no balanço de pagamentos. Por causa dessa crise, instou ao Partido Comunista Chinês (PCC) que mudasse drasticamente para um modelo de desenvolvimento orientado pelas exportações, por meio de uma enorme desvalorização em uma única tacada do yuan em 1994 e uma série de reformas que precipitaram o declínio da economia rural e desencadearam uma onda de migração de trabalhadores rurais para as zonas de processamento das exportações localizadas em sua costa. Esse processo conectou firmemente a China à ordem global de livre comércio. A China, então, tornou-se um redemoinho que sugou empregos da manufatura de todo o mundo, tornando-se a "fábrica do mundo", apesar de a maioria das fábricas orientadas para exportação instaladas na China serem fortemente controladas e exploradas pelas corporações transnacionais sediadas no norte global (HUNG, 2015, cap. 3). 
O capital norte-americano, tendo muito se beneficiado da terceirização das manufaturas para a China, pressionou persistentemente Washington para que as diferenças políticas entre a China e os Estados Unidos não ficassem no caminho. Os esforços dessa pressão resultaram na decisão da Administração Clinton de desvincular a renovação do status da China como "nação mais favorecida" (NMF) de qualquer preocupação com os direitos humanos em 1994, garantindo à China o status permanente de NMF em 2000 e dando a ela, finalmente, acesso à Organização Mundial do Comércio (OMC) em 2001.

A onda de terceirização da produção em direção à China, bem como a corrida ao fundo do poço pelas economias em desenvolvimento para atrair capital do norte, que a China ajudou a desencadear, permitiram às empresas transnacionais (ETN) acumular lucros extraordinários, que foram então canalizados para o mercado financeiro no próprio norte global, cuja expansão estimula a demanda por produtos manufaturados provenientes da China. Isso levou a uma rápida expansão da capacidade industrial chinesa, mas também a bolhas financeiras e de consumo via crédito nos Estados Unidos e em outros países centrais. A superprodução na China e o consumo excessivo nos EUA constituíram o desequilíbrio econômico global que levou ambos a uma aparente prosperidade durante a maior parte dos anos 2000, instigando a narrativa da "Chiamérica" ou do G2 como a nova base da ordem econômica global.

É notório como essa prosperidade insustentável alimentada pelo jogo econômico global e pelos desequilíbrios domésticos na China e nos Estados Unidos acabou em 2008. A bolha da expansão financeira e do consumo via crédito nos Estados Unidos colapsou, dando início a uma longa derrapagem da economia norte-americana. A economia puxada pelas exportações da China também entrou em colapso no final de 2008, mas Pequim logo desenhou um processo bem-sucedido de recuperação em 2009-2010, por meio de uma enxurrada de empréstimos dos bancos estatais direcionados aos investimentos em ativos fixos. Foi essa forte recuperação da China em meio ao fraco desempenho norte-americano que gerou a percepção de que a China teria substituído os Estados Unidos como motor principal do capitalismo global.

A forte recuperação chinesa também levou muitos a argumentarem que a economia da China não era tão dependente das exportações, uma vez que pôde retornar ao crescimento de dois dígitos em 2009-2010, dependendo principalmente do investimento doméstico a despeito do lento crescimento das exportações para o norte. Essa tese, contudo, é equivocada e míope. Durante os anos de boom, as exportações chinesas, em conjunto com o influxo de capital voltado à produção para exportação, representaram grande parte do crescimento das reservas internacionais da China, sobretudo na forma de ativos em dólares norte-americanos. Sem a expansão das reservas, Pequim não teria podido aumentar a oferta monetária imprudentemente na 
forma de empréstimos estatais abundantes e baratos. Dessa forma, o setor exportador e as crescentes reservas que ele trouxe tornaram possíveis os investimentos via empréstimos entre 2000 e 2008, sem repetir o mal-estar econômico de muitas das economias do sudeste asiático às vésperas da crise financeira de 1997-1998, quando a farra de anos de investimentos alimentados por dívidas e sem adequada correspondência no crescimento das reservas internacionais prejudicou suas moedas e desencadeou a fuga de capitais.

No entanto, a situação mudou depois de 2008. O enfraquecimento do motor exportador e a imprudente expansão do investimento durante a recuperação de 20092010 criaram uma gigantesca bolha de dívida que não correspondia mais à expansão nas reservas internacionais. Entre 2008 e o início de 2015, a dívida total da China passou de $148 \%$ do PIB para $282 \%$, ultrapassando o nível dos Estados Unidos e da maior parte dos países em desenvolvimento. Encerrou-se o longo período de aumento das reservas internacionais da China, que passaram a diminuir em 2014. Enquanto isso, muitas das obras e da infraestrutura resultantes da recuperação econômica via dívida não serão lucrativas, pelo menos não em breve. O pagamento e o serviço da dívida são duvidosos, e uma grande bomba-relógio da dívida se formou. A China, portanto, já não tem mais espaço para crescimento por meio de investimento em ativos fixos enquanto o setor exportador ainda enfrenta dificuldades. Para piorar a situação para o capital, a escalada da resistência camponesa e das agitações trabalhistas desde os anos 1990 forçou o Partido Comunista a fazer concessões por meio da melhoria nas condições econômicas do campo (reduzindo o fluxo de migração de trabalhadores rurais em direção aos setores exportadores da costa) e das condições de trabalho nas fábricas. Essas concessões aumentam o nível salarial e pressionam ainda mais a rentabilidade do capital (HUNG, 2015, cap. 6).

A capacidade produtiva e a infraestrutura, os apartamentos, as minas de carvão, as siderúrgicas etc., que se expandiram rapidamente durante o período de boom e de recuperação pós-2008, tornaram-se excessivos com a queda na taxa de lucro. Isso levou a China a uma típica crise de superacumulação simbolizada pelas muitas cidadesfantasma e pelas fábricas fechadas por todo o país. A perda de impulso da economia chinesa depois da grande recuperação de 2009-2010 é ilustrada pelo índice dos gerentes de compras, o Purchasing Managers Index (PMI), no setor da manufatura, que é um dos principais indicadores do setor industrial. Um PMI superior a 50 dá sinais de expansão da indústria, enquanto um valor inferior a 50 mostra contração. Pode-se notar que, depois da recuperação de 2009-2010, o índice continuou a cair e agora está flutuando em torno de 50, a linha de estagnação, que é uma mudança significativa em relação à contínua expansão anterior a 2008. 


\section{Gráfico 1 - Índice dos Gerentes de Compras (PMI) no} setor da manufatura na China, 2006-2015

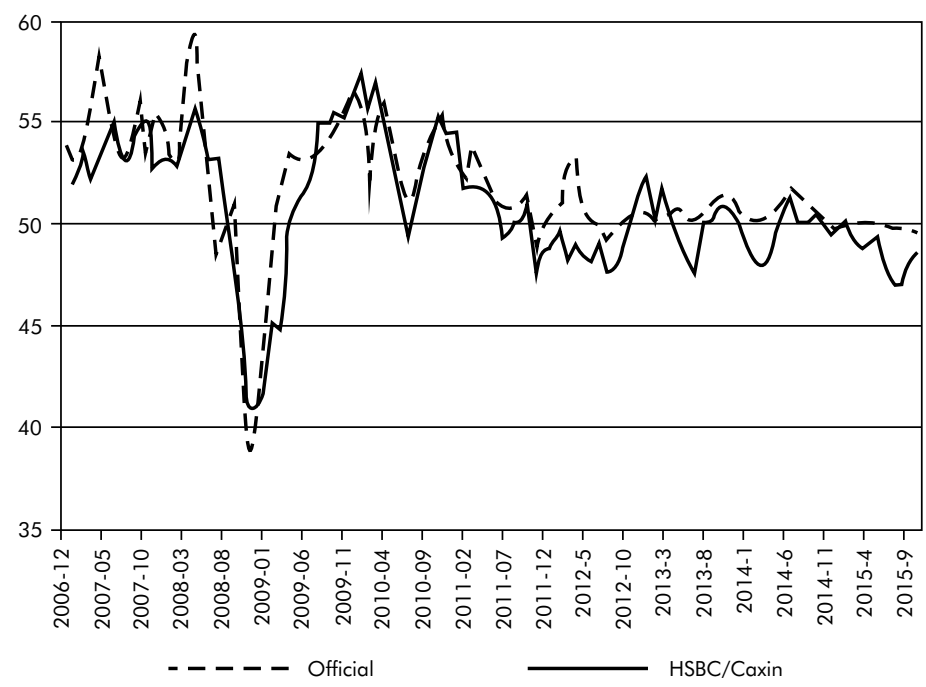

Fonte: Escritório Nacional de Estatísticas da China, HSBC, Caixin.

Essa crise de superacumulação da economia chinesa está na origem do recente colapso do mercado de ações e do começo da fuga de capitais que impulsionam a forte desvalorização da moeda chinesa.

Crises de superacumulação são tão velhas quanto o próprio capitalismo. Como Lênin (1917) já diagnosticava há muito tempo em sua obra Imperialismo, Etapa Superior do Capitalismo, uma crise de superacumulação dentro de uma economia doméstica leva os capitalistas a exportar capital em busca de lugares com taxas de lucro mais altas. Foi exatamente assim que o capital industrial do centro foi realocado para a Ásia e para a China depois dos anos 1970. Agora é a vez da China se tornar a vítima desse efeito e ter a necessidade de exportar capital.

Desde o início dos anos 2000, as exportações de capital da China tiveram um grande aumento. O investimento direto da China saltou de US\$ 28 bilhões em 2000 para US\$ 298 bilhões em 2012, apesar de ainda ser pequeno se comparado com o de economias capitalistas avançadas menores, como Cingapura (HUNG, 2015).

As empresas estatais, principalmente as de energia e infraestrutura, apoiadas pelas grandes reservas internacionais provenientes do setor exportador, estiveram na vanguarda do investimento externo chinês no sul global, mais notavelmente na África e no sudeste asiático. A produção chinesa vem se transferindo para países com salários mais baixos, como a Tanzânia e o Vietnã. É esse mesmo impulso de exportação do capital excedente que norteia a recente ambição chinesa em criar uma rede de portos, 
ferrovias e rodovias ligando a China à Europa, através da Ásia Central e do Oceano Índico, conhecida como One Belt, One Road. Todavia, como Lênin previu, o impulso de exportar capital para fora inevitavelmente faria com que os Estados de origem projetassem seu poder militar e político no exterior, com objetivo de proteger o circuito de acumulação do capital exportado, levando a uma expansão imperialista e a uma rivalidade interimperialista com outras potências exportadoras de capital. Lidar-se-á com isso logo mais.

Nas próximas duas seções, nós discutiremos como a ascensão econômica da China, conduzida pelo crescimento orientado pela exportação e pelo investimento em ativos fixos, bem como a necessidade crescente de exportação de capital para o mundo, remodelaram o contexto de desenvolvimento e a balança geopolítica na Ásia e no restante do mundo.

\section{NOVOS CONTORNOS DE DESENVOLVIMENTO NO SUL GLOBAL}

Como se viu, o boom capitalista da China foi promovido por legados e circunstâncias únicos, que seriam de difícil replicação em outros países em desenvolvimento. A questão é como esse fenômeno mudou as condições econômicas mundiais que moldam as perspectivas de desenvolvimento de outras economias do sul global. Os efeitos que o boom chinês tem sobre a África, a América Latina e a Ásia são contraditórios.

Ao longo da última década, as crescentes relações comerciais e de investimento da China com outros países em desenvolvimento, particularmente os africanos, atraíram cada vez mais atenção e provocaram debates fervorosos no mundo desenvolvido e em desenvolvimento. Em muitos textos jornalísticos e polêmicos sobre essas questões, alguns veem a China como nova salvadora do mundo em desenvolvimento, aquela que ajudaria a resgatar países em desenvolvimento oprimidos da tirania do neocolonialismo das potências ocidentais. Diferentemente dos países ocidentais e das organizações financeiras internacionais dominadas pelos Estados Unidos e pela Europa, que muitas vezes vinculam os auxílios, os empréstimos, os investimentos e os acordos comerciais a pactos de reforma e políticas que favorecem os interesses ocidentais, a China teoricamente age como fonte alternativa de negócios e investimentos sem condicionalidades. Por outro lado, há autores que acusam a China de ser apenas outra potência neocolonial, que busca extrair recursos naturais de outros países em desenvolvimento para seu próprio desenvolvimento, negligenciando a sustentabilidade de longo prazo daqueles. Ou pior, a China é vista como um país mercantilista, que busca apenas expandir agressivamente seu mercado para exportações à custa dos setores manufatureiros de outros países em desenvolvimento. Alguns alertam que o crescente 
apetite por recursos e produtos manufaturados exportáveis e baratos tem desindustrializado muitas economias do Sul, tornando-as novamente dependentes da exportação de recursos naturais.

Pesquisas acadêmicas mais sérias têm emergido nos anos recentes com objetivo de resolver essas alegações conflitantes sobre o impacto da China nos outros países. $\mathrm{O}$ que estes estudos encontram, na verdade, é um quadro mais complexo do que o que tem sido capturado pelas polêmicas de políticos e comentaristas críticos.

\subsection{EXPORTADORES DE COMMODITIES VS EXPORTADORES DE MANUFATURAS}

Na literatura sobre desenvolvimento, há uma plenitude de trabalhos sugerindo a virtude da diversificação da pauta exportadora dos países em desenvolvimento para além dos recursos naturais. Do passado colonial à era pós-independência, muitos países em desenvolvimento ficaram presos a uma economia de monocultura, apoiando-se na exportação de um único ou poucos produtos agrícolas e matérias-primas para os países desenvolvidos. A flutuação nos preços das commodities no mercado mundial, muito além do controle destes exportadores, fez suas trajetórias de desenvolvimento extremamente instáveis (excetuando-se apenas os exportadores de petróleo). Mesmo que as commodities que eles exportam gozem de preços estáveis e decentes, suas economias ainda são vulneráveis à "doença holandesa" ou "maldição dos recursos naturais": a demanda global pelas suas commodities valoriza suas moedas, reduzindo, assim, o desenvolvimento de setor industrial voltado para exportação e encorajando o consumo conspícuo de bens de luxo importados pela elite. Segue-se que, se os países em desenvolvimento aspiram fomentar um crescimento equilibrado e sustentável, o setor de exportação de recursos naturais, assim como os interesses ligados a ele, precisa ser comprimido para abrir espaço para o crescimento de outros setores, sobretudo o industrial (e.g. KARL, 1997; SACHS e WARNER, 1995; SHAFER, 1994; GALLAGHER e PORZECANSKI, 2010).

O esforço de reduzir a dependência das exportações de recursos naturais é exatamente o que muitos dos governos desenvolvimentistas têm feito no pós-guerra, seja por meio da industrialização via substituição de importações (ou seja, criando barreiras à importação de produtos estrangeiros para apoiar as indústrias nacionais) ou da industrialização via exportação (subsidiando e promovendo os produtos das indústrias locais). A ascensão da China rompeu com esse esforço em muitos dos países em desenvolvimento. Primeiro, a crescente demanda por petróleo, matérias-primas, produtos agrícolas e similares pela China impulsionou o preço das commodities, gerando grandes retornos aos exportadores de commodities de todo o globo, seja por ex- 
portação direta à China ou indiretamente,pela subida geral do preço das commodities por causa da demanda chinesa. Relatório do FMI confirma que

a China está se tornando paulatinamente mais e mais importante para os mercados de commodities. Seu papel no mercado e seus impactos no comércio mundial e nos preços variam conforme a commodity; em particular, a China tornou-se o principal importador de metais comuns e matérias-primas agrícolas, com uma menor, porém crescente, importância no mercado de alimentação e de energia. (ROACHE, 2012, p. 21)

Como consequência do aumento dos lucros nos exportadores de commodities, as indústrias de mineração e o agronegócio se expandiram em todo o mundo em desenvolvimento, se contrapondo às políticas desenvolvimentistas. Por exemplo, as terras usadas para o cultivo de soja no Brasil duplicaram entre 1990 e 2005 . Isso levou a uma vasta expansão da agricultura em terras ambientalmente sensíveis da fronteira amazônica para atender à demanda chinesa, que constitui 42,7\% do mercado de exportações de soja do Brasil (GALLAGHER e PORZENCANSKI, 2010, p. 31-32). A mineração de cobre no Chile e em outros países latino-americanos também se expandiu significativamente em período similar, sendo que o total de exportações de cobre da região aumentouem 237,5\% entre 2000 e 2006, um crescimento puxado quase exclusivamente pela China (GALLAGHER e PORZENCANSKI, 2010, p. 22). O mesmo aconteceu na África. Além dos países produtores de petróleo, como Sudão e Nigéria, países que são ricos em minerais metálicos se beneficiam do crescimento da demanda chinesa. $\mathrm{O}$ crescimento maciço na exportação de cobre da Zâmbia é um desses casos.

Enquanto a China ajuda a impulsionar a exportação de matérias-primas de outros países em desenvolvimento, seu eficiente setor de manufaturas de baixo custo aumentou a pressão competitiva nos setores manufatureiros de outros países. Alguns argumentam que a própria gênese da industrialização via exportação da China nos anos 1990 está conectada aos problemas econômicos dos outros exportadores asiáticos, como Malásia e Tailândia, e que a China contribuiu para a eclosão da crise financeira asiática de 1997-1998. A desvalorização de 50\% em uma única tacada do renminbi (RMB), em 1994, inaugurou a era de exportação de produção de baixo custo na China (HUNG, 2015). Isso fez com que as indústrias dos vizinhos do sudeste asiático, que já sofriam com o aumento do nível salarial e a apreciação cambial, ficassem ainda menos competitivas. A consequente desaceleração econômica, junto com os empréstimos frouxos e outras forças que moveram esses países da produção em direção à especulação financeira, abriu caminho para a crise financeira asiática, segundo alguns autores argumentam (KRAUSE, 1998). 
Em relação às indústrias latino-americanas, Kevin Gallagher e Robert Porzecaski compilaram um índice para analisar o quanto as exportações industriais chinesas ameaçam as sul-americanas. Segundo eles, todos os maiores países latino-americanos têm mais de $80 \%$ de suas exportações industriais sob ameaça direta ou parcial da China (GALLAGHER e PORZECANSKI, 2010, p. 50). Dessa maneira, os mercados doméstico e internacional para os produtos latino-americanos começaram a ser substituídos pelos correspondentes chineses.

\subsection{VARIEDADES DAS RESPOSTAS DOS PAÍSES EM DESENVOLVIMENTO AO BOOM DA CHINA}

Considerando as tendências de expansão do setor de exportação de matérias-primas e do aumento nas pressões competitivas sobre as indústrias domésticas, pode-se ver que a ascensão da China criou condições que podem levar à desindustrialização e ao retorno à dependência da exportação de recursos naturais no mundo em desenvolvimento. Entretanto, se e o quanto essa mudança danificaria ou beneficiaria o desenvolvimento de longo prazo dos países individualmente varia e depende muito da dinâmica da economia política de cada país.

Por exemplo, a maior parte dos países da América Latina tem empresas de mineração reguladas ou sob controle de seus governos, possuindo, assim, alguma influência sobre o preço e o volume de produção do material demandado. Eles são, então, capazes de negociar com a China e com outros clientes para chegar a acordos que maximizem seus interesses. Os governos poderiam também estabelecer instituições que direcionem os lucros do setor de recursos naturais em expansão para outros usos, incluindo investimentos de longo prazo, apoio à diversificação econômica e alívio da pobreza. Há alguns casos excepcionais de sucesso. Por exemplo, o governo chileno instituiu um fundo de estabilidade econômica e social que suga parte dos lucros do setor de exportação de recursos durante o período de boom e gasta essa poupança para intervir no mercado de câmbio, em investimentos e em estímulos fiscais, durante períodos de recessão. Isso suaviza o impacto da volatilidade no preço das commodities na economia como um todo, mas mesmo assim o Chile está se tornando mais e mais dependente das exportações de matérias-primas (GALLAGHER e PORZECANSKI, 2010, p. 32-7). Como outro exemplo, o governo brasileiro, no período do presidente Lula, criou uma série de programas eficientes de redistribuição de renda (como o bem conhecido programa de transferência condicional de renda, Bolsa Família) logo quando a economia brasileira estava avançando, impulsionada pela exportação de matérias-primas. Essas instituições de alguns países latino-americanos garantem que o lucro proveniente da 
bonança das matérias-primas seja distribuído de modo mais uniforme e que o superavit seja direcionado para financiamento de investimentos de longo prazo em educação, infraestrutura e fortalecimento de outros setores econômicos cruciais ao crescimento sustentável do país.

Em contraste com a América Latina, onde vários dos setores de extração de recursos foram baseados em empresas que são domésticas ou mesmo estatais, muitos países africanos não têm empresas mineradoras locais competitivas e dependem de empresas estrangeiras para extrair seus recursos. Suas crescentes exportações de matérias-primas para a China, sem exceção, são acompanhadas pelo investimento das empresas estatais chinesas no setor de mineração. Em muitos casos, as companhias estatais chinesas, junto a outras mineradoras transnacionais, possuem e comandam toda a cadeia da commodity, dos sítios de mineração até os portos. Sob tais circunstâncias, os governos africanos estão em posições muito menos favoráveis ao negociar com seus parceiros chineses, que tendem a extrair e enviar os materiais que necessitam, no volume e tão rápido quanto querem, sem muita consideração com o impacto de longo prazo na economia e meio ambiente locais.

Ainda muito se debate se as práticas das corporações chinesas são piores ou melhores do que as das corporações ocidentais. Porém, uma coisa certa é que essas empresas tendem a colocar seus interesses acima das perspectivas de desenvolvimento de longo prazo dos seus anfitriões. A indústria de cobre na Zâmbia é um exemplo de que as empresas mineradoras chinesas têm se expandido com base na flexibilização ou desregulamentação do trabalho e em aliança comum governo corrupto que busca maximizar seus ganhos no curto prazo (HAGLUND, 2009; LEE, 2009).

$\mathrm{Na}$ mesma linha, o impacto da competição com os produtos chineses varia de país para país, dependendo do lugar em que este ocupa nas cadeias globais de valor. De acordo com Kevin Gallagher e Roberto Porzecanski (2010), a maioria dos países latino-americanos enfrenta pressão competitiva dos fabricantes chineses, sendo que alguns têm maiores dificuldades do que outros. O México se destaca como um país que sofreu o maior impacto em razão de sua estrutura industrial. As indústrias exportadoras do México foram mais atingidas pelas da China porque ambas dependem fortemente do mercado norte-americano.

Se olharmos mais amplamente para comparar o impacto da produção chinesa em outras economias asiáticas e latino-americanas, nós observaremos uma imagem mais variada. Como se viu em uma seção anterior, depois do impacto inicial da ascensão chinesa como potência exportadora de bens industriais, muitos dos vizinhos asiáticos ajustaram suas estruturas industriais para se integrarem melhor com a China. Depois que essas economias mudaram o foco de sua produção para produtos de maior ou menor valor nas cadeias globais em relação ao que era produzido pela China, esses 
países não podiam mais competir em pé de igualdade com os chineses. Além disso, uma grande parte do setor de exportação chinês concentra-se na montagem, o que significa que a China importa componentes de outros fabricantes asiáticos e os monta, exportando-os para mercados finais como itens "made in China". Assim, uma rede regional de produção desenvolveu-se na Ásia, na qual os fabricantes abastecem a China com componentes e maquinário e se beneficiam da ascensão chinesa como potência industrial. As economias asiáticas encontram-se em uma situação bastante diferente das economias latino-americanas, que entram nesta rede de produção global sinocêntrica como fornecedoras de recursos naturais em vez de ofertantes de componentes industriais.

\section{O AVANÇO GEOPOLÍTICO DA CHINA NA ÁSIA E NO MUNDO}

Conforme a influência econômica da China na Ásia tem aumentado, o país começou a empregar seu poder como maior parceiro comercial de muitos de seus vizinhos para estabelecer sua liderança regional. A abordagem chinesa em relação aos seus vizinhos pode ser precursora da sua abordagem para com outras partes do mundo. Apesar de a China nunca ter sido uma potência política com alcance global em toda a história,

o império chinês exerceu hegemonia na Ásia antes das potências imperiais ocidentais derrubarem a ordem asiática pré-moderna. Alguns veem a trajetória de ascensão chinesa na Ásia em um mundo de pós-hegemonia dos Estados Unidos como, pelo menos parcialmente, um ressurgimento da ordem sinocêntrica regional pré-moderna, que segue uma lógica bastante diferente se comparada ao sistema internacional vestfaliano desenvolvido na Europa. Para entender como a ascensão política da China está contribuindo para remodelar a ordem asiática, precisa-se ter uma perspectiva histórica nas relações da China com o mundo desde os tempos imperiais.

\subsection{O RESGATE CONTESTADO DA ORDEM TRIBUTÁRIA SINOCÊNTRICA NA ÁSIA}

De acordo com o historiador japonês Takeshi Hamashita (2008), a visão de mundo chinesa pré-moderna foi dominada por um universalismo no qual a distinção entre entidades "dentro" do império e aquelas "fora" do império não estão bem definidas. O mundo, de acordo com a visão imperial chinesa, é constituído por círculos concêntricos centrados no imperador, que governa diretamente províncias localizadas no círculo externo imediato e tributa vassalos nos círculos mais distantes. Essa ordem mundial, divergindo do modelo de império Ocidental, que se originou no período romano, 
não foi fundada na mera extração tributária pelo centro. Ela também se diferencia do sistema de Vestefália, baseado na balança de poder entre Estados. Em vez disso, sua operação se assegura no princípio da benevolência do centro e da lealdade recíproca da periferia. Os vassalos do império chinês enviavam presentes para a capital imperial em missões de tributo. Em contrapartida, essas missões obtinham presentes de maior valor do imperador. Sob esse sistema, governantes de estados tributários conquistavam legitimidade ao obter apoio do imperador chinês, e a lealdade desses Estados era fundamental para a segurança da fronteira do império chinês. Por vezes, o império chinês enviava tropas para derrubar governantes subordinados que se recusavam a jurar lealdade à China e instaurava governantes aliados (KANG, 2010).

Esse sistema de subordinação tributária sinocêntrico foi consolidado durante a dinastia Tang (618-906 d.C.) e tinha Xi'an como a capital do império que recebia periodicamente missões de honra da Ásia Central. Durante a dinastia Song, quando as invasões nômades do norte empurraram o centro de gravidade do império chinês para o sul, as atividades marítimas oficiais e extraoficiais chinesas começaram a crescer na Ásia, até culminarem na dinastia Ming (1368-1644 d.C.), quando o sistema tributário sinocêntrico se expandiu para o sudeste asiático e o Japão. Com o crescimento da troca privada marítima na Ásia, as missões de prestação de tributos ganharam não apenas a partir da troca recíproca de presentes com o imperador chinês, mas também com as atividades de comércio conduzidas por mercadores que acompanhavam essas missões à China. Com a ascensão do comércio juntamente das missões tributárias, o sistema de tributos sinocêntrico tornou-se, na prática, um sistema tributo-comercial ("tributetrade system") (HAMASHITA, 2008; KANG, 2010).

Esse sistema tributo-comercial não foi sempre pacífico. Ocasionalmente, potências ascendentes na região tentaram desafiar a hegemonia chinesa, fosse recuando da sua conexão político-econômica com a China, fosse construindo suas próprias redes tributárias e comerciais. Por exemplo, após Hideyoshi reunificar o Japão, ele imaginava tomar o lugar da China como centro da Ásia, invadindo a Coreia na década de 1590. Seu esforço falhou com a expulsão das forças japonesas da Coreia pelo exército chinês. Seu sucessor, Shogun Tokugawa, adotou a política de isolamento, que proibiu o comércio com a China e parou de enviar missões tributárias após 1600 (HOWE, 1996). O Japão também estabeleceu relações tributárias com o reino de Ryukyu, que havia sido vassalo da China. O reino de Ryukyu foi incorporado ao Japão moderno nos anos de 1870 e constitui hoje a prefeitura de Okinawa.

De acordo com Hamashita, o desenvolvimento das relações internacionais modernas na Ásia precisa ser lido à luz da transformação desse sistema tributo-comercial proveniente da Ásia. A desintegração do sistema sinocêntrico com a colonização ocidental dos vassalos tributários chineses - como Birmânia e Vietnã - abriu espaço para 
o Japão, que se industrializou de forma bem-sucedida e construiu um Estado centralizado moderno após a restauração Meiji, de 1868, dando seguimento à sua ambição de retirar a centralidade chinesa na Ásia. O esforço de construir um "grande círculo de co-prosperidade na Ásia", que começa com a colonização japonesa em Taiwan e na Coreia em 1895 e 1905, o estabelecimento de um Estado marionete na Manchúria em 1931, seguido da invasão direta à China em 1937 e breve colonização de uma série de estados do sudeste asiático durante a II Guerra Mundial foram, de certa forma, uma continuação do sonho de Hideyoshi de uma ordem na Ásia centrada no Japão.

Após o colapso do império japonês com o fim da II Guerra Mundial, a ordem internacional do leste asiático foi substituída pela ordem da Guerra Fria. Os Estados Unidos tomaram o lugar do Japão no domíniodos mares da Ásia, provendo segurança econômica e militar para Japão, Coreia, Hong Kong, Cingapura e boa parte do sudeste asiático. A China, ao se tornar comunista em 1949, era a princípio parte do bloco soviético. Entretanto, a ordem da Guerra Fria na Ásia tornou-se mais complexa com a ruptura da China em relação à União Soviética, que a fez uma potência autônoma na região, independente tanto dos Estados Unidos quanto do bloco soviético.

Na década de 1950, a China, embora ainda fosse formalmente aliada aos soviéticos, já havia começado a se tornar um defensor-chave do movimento de não alinhamento que buscava abrir espaço político autônomo para os países recém-independentes e em desenvolvimento. Após o racha sino-soviético no início dos anos 1960, a diplomacia revolucionária chinesa se tornou totalmente independente da União Soviética, e o apoio financeiro e militar chinês aos regimes e movimentos revolucionários, incluindo os da Coreia do Norte, Camboja e outros Estados do Sudeste Asiático, relembrou a relação de apadrinhamento entre o império chinês e as minidinastias nos estados vassalos vizinhos. Nos tempos de Guerra Fria, tal resgate de uma ordem tributária sinocêntrica foi apenas parcial. A influência chinesa sobre seus vizinhos era muito limitada, uma vez que muitos, como a Coreia do Norte, também eram submissos à União Soviética, e as forças políticas patrocinadas pela China eram, em geral, movimentos de guerrilha, como os partidos comunistas nas Filipinas e Malásia, que não estavam no poder (BRAUTIGAM, 2011, p. 29-40).

Com o fim da Guerra Fria e a reestruturação econômica da China, o ressurgimento de tal sistema tributo-comercial sinocêntrico tornou-se mais bem desenvolvido. Com a China se tornando o maior exportador de bens finais manufaturados da Ásia, uma divisão regional do trabalho emergiu e, com isso, os vizinhos desse país se especializaram em exportar bens de capital e componentes para ele, gerando uma rede de produção sinocêntrica, como vimos na penúltima seção. Além do crescimento da dependência econômica dos vizinhos em relação à China via comércio, esse país também tem sido ativo na provisão de investimentos, empréstimos e outros tipos de assis- 
tência econômica a seus vizinhos mais pobres (BOWER, 2010; LUM et al., 2009). Os vários projetos de infraestrutura no Camboja e Myanmar levados a cabo por empresas estatais chinesas ou financiados por empréstimos de bancos estatais chineses são bons exemplos (O'CONNER, 2011; GRIMSDITCH, 2012).

Conforme a dependência econômica desses países asiáticos, ricos e pobres, em relação à China se aprofunda, ela ganha mais envergadura para influenciar os governos dos vizinhos. Embora o governo chinês sempre negue a ligação, a ameaça de cortar laços econômicos com países se tornou uma arma diplomática sempre disponível. A respeito das disputas territoriais da China com os países do sudeste asiático e o Japão, ela raramente hesita em ameaçar ou usar sanções econômicas em quem quer que considere violar as reivindicações de soberania chinesa (REILLY, 2012). Por exemplo, quando a disputa territorial da China com o Japão pelas Ilhas Diaoyu/Senkakus escalou, em 2012, no momento em que o governo japonês nacionalizou as ilhas, a agência oficial China's Daily ameaçou explicitamente impor sanções econômicas ao Japão, recorrendo à cláusula de "exceções de segurança" da OMC. Ameaças similares foram sugeridas em relação às disputas territoriais com as Filipinas e o Vietnã pelas Ilhas Spratly no Mar do Sul da China.

Para ser exato, a ascensão dessa nova ordem asiática, com peso crescente e centralidade da China, está longe de ser uma simples réplica da ordem tributária e comercial sinocêntrica pré-moderna. Por um lado, a antiga ordem tinha no confucionismo o elemento cultural de fundação, o que justificava a prática de reciprocidade entre o centro e a periferia, além da benevolência daquele em relação a este. Tal base cultural também incentivou a maior parte das nações asiáticas a identificarem na China um modelo de governo e economia a ser seguido. Hoje, o crescimento da centralidade da China nessa nova ordem internacional asiática, pelo contrário, não está apoiado em nenhuma raiz cultural comum, e sim ancorado em interesses econômicos puros e na realpolitik. Por outro lado, a China era a única potência dominante no sistema sinocêntrico pré-moderno, enquanto hoje o país se defronta com a hegemonia residual dos Estados Unidos na região.

A falta de um elemento de fundação cultural e a competição com os Estados Unidos são os maiores obstáculos para o crescimento da influência geopolítica chinesa. Motivados apenas por interesses econômicos e na falta de elementos de admiração cultural na relação com a China, a aliança dos estados asiáticos com a China tem sido, na melhor das hipóteses, pragmática e contingencial. A presença prolongada norteamericana também deu a esses estados a oportunidade de jogar as potências (China e Estados Unidos) uma contra a outra nas suas negociações. Por exemplo, a junta militar de Myanmar, que tem sido apoiada por Pequim e se beneficiou dos seus laços econômicos com a China em meio às sanções dos países ocidentais desde os anos 1990, sen- 
tiu-se crescentemente insegura devido à dependência dos investimentos provenientes da China. Essa insegurança aliada à insatisfação popular que algumas estatais mineradoras chinesas geraram no país motivou a junta a tentar uma reforma política em troca da normalização das relações com os Estados Unidos e o mundo ocidental, iniciada por volta de 2011. Enquanto o governo de Myanmar manteve sua relação com a China, marcada pela inauguração de um gasoduto em 2013 construído pela China NationalPetroleum Corporation, que conecta o Golfo de Bengala à província de Yunnan, no sudoeste da China, passando por Myanmar, as relações entre Myanmar e os Estados Unidos evoluíram ao ponto de o país ser convidado para o posto de observador do exercício militar Estados Unidos-Tailândia no começo de 2013. A reforma política em Myanmar eventualmente levou à eleição de 2015, na qual a oposição, liderada por Aung San Suu Kyi, teve uma vitória esmagadora.

Além de Myanmar, Cingapura, Taiwan, Coreia do Sul, as Filipinas e diversos outros países asiáticos fortaleceram seus laços econômicos e político-militares com os Estados Unidos enquanto gozam de crescente integração econômica com a China. A Parceria Transpacífico (TPP), um acordo de livre comércio entre os Estados Unidos e seus aliados da Ásia-Pacífico, não incluindo a China, teria sido outro caso em questão.

O caminho da crescente centralidade da China na Ásia evidencia a contradição da ascensão geopolítica da China em geral: o crescimento da influência política da China nos seus vizinhos é produto direto da sua crescente centralidade econômica. Mas sua influência política também é enquadrada pela dominância contínua dos Estados Unidos e pela reação contra o excesso de dependência econômica desses países em relação à China. Essa contradição não está restrita à geopolítica da Ásia, mas também se reflete na ascensão contraditória da influência da China em outras regiões do mundo e no mundo como um todo.

\section{FABRICANDO UMA NOVA POTÊNCIA IMPERIAL?}

A prática chinesa de estender sua assistência econômica a outras nações em desenvolvimento em troca de sua lealdade não está restrita ao leste asiático. Desde pelo menos os anos 1960, a China tem sido ativa em financiar movimentos revolucionários e governos em outras regiões em desenvolvimento, a África em particular, com assistência técnica e financeira. Nos anos 1960, tal esforço de Pequim estava ligado à competição com a União Soviética pelo papel de liderança no Terceiro Mundo após o racha sinosoviético no movimento comunista internacional. Na década de 1970, após a normalização das relações entre China e Estados Unidos, o esforço de Pequim em conseguir apoio das nações africanas se motivava principalmente para obter votos na Assembleia 
das Nações Unidas no intuito de endossar seu pleito por um assento na ONU no lugar da República da China em Taiwan (BRAUTIGAM, 2011, p. 67-70).

Após o início das reformas econômicas dos anos 1980, a atenção da China para a África diminuiu. Contudo, tal atenção se renovou com mais vigor nos anos 2000, quando o crescimento econômico acelerado da China impulsionou Pequim de volta à África como estratégia de garantir a oferta de petróleo e outras matérias-primas. Do ponto de vista de Pequim, é importante estabelecer seus próprios investimentos nas operações de mineração na África e não ficar vulnerável às indústrias de extração de recursos naturais dominadas pelas potências Ocidentais.

A abordagem geral chinesa junto aos exportadores africanos de recursos naturais é de se aproximar de quem quer que esteja no poder, com empréstimos, ajuda externa e projetos de investimento em infraestrutura. A China não discrimina pelo tipo de regime, e seus esforços têm atingido tanto governos autoritários quanto democráticos. Os investimentos chineses se espalham mais uniformemente na região em diferentes países e apresentam termos mais generosos para os receptores (BRAUTIGAM, 2011). Como se viu na seção anterior, os investimentos e o comércio crescentes da China com a África tiveram impactos socioeconômicos distintos, dependendo das instituições locais e da política no país anfitrião. Embora o tamanho da assistência econômica chinesa trilhe aquela oferecida pelas potências ocidentais, sobretudo pelos Estados Unidos (HUNG, 2015), a assistência chinesa geralmente traz novos e positivos ganhos ao continente, uma vez que sua presença cria pressões competitivas entre países, desenvolvidos e em desenvolvimento, oferecendo melhores condições de negociação para as nações africanas.

Muitos Estados africanos mantêm reciprocidade na sua relação com a China, retribuindo os favores econômicos com apoio a Pequim em questões políticas, como o episódio de Taiwan e o Dalai Lama. Em 2011, o Dalai Lama planejou visitar a África do Sul no $80^{\circ}$ aniversário do prêmio Nobel e arcebispo Desmond Tutu, mas o governo da África do Sul não concedeu visto para a visita, apesar do convite de Tutu, tendo já sido negada a entrada de Dalai Lama ao país anteriormente em 2009. A oposição descreveu a ação do governo como ilegítima e criticou a decisão como sendo feita sob pressão da China. Ao mesmo tempo, a presença crescente da China ofereceu a esses Estados novas fontes de apoio e oportunidades financeiras e, portanto, nova autonomia para resistir às demandas políticas dos Estados Unidos e de outras potências Ocidentais.

Entretanto, assim como muitos vizinhos do sudeste asiático têm se sentido inseguros em relação ao crescimento da dependência em relação à China, alguns líderes africanos começaram a expressar sua preocupação com o "colonialismo chinês”. Quando essa questão começou a ser discutida por políticos e acadêmicos ocidentais nos anos 2000, foi naturalmente desqualificada como uma discussão hipócrita, baseada na in- 
quietação ocidental de perder influência sobre o continente para a China. Nos anos 2010, a discussão sobre o colonialismo chinês emergiu de dentro da África, quando movimentos de oposição começaram a atacar os governos, acusando-os de se tornarem subordinados aos interesses chineses. Por exemplo, na eleição da Zâmbia, em 2011, o partido de oposição fez sua campanha baseada numa plataforma anti-China e foi bem-sucedido em substituir o partido no poder. No contexto da cúpula dos BRICS, da qual participaram Brasil, Rússia, Índia, China e África do Sul, em Durban, na África do Sul, em março de 2013, diversas organizações não governamentais e ativistas organizaram uma reunião alternativa e cunharam o conceito de "subimperialismo", colocando a China e os demais países dos BRICS como potências subimperialistas atuando no continente. Alguns chegam a afirmar que o entusiasmo dos BRICS em expandir sua presença no continente relembra a "partilha da África" entre as potências imperiais europeias após a Conferência de Berlim em 1885 (BOND, 2013).

Essa preocupação com a influência crescente da China na África tem sido tão forte e difundida que mesmo governos com relações muito próximas coma China têm tido de "se posicionar". Em março de 2013, logo antes da cúpula dos BRICS, em Durban, o então governador do Banco Central da Nigéria, que havia sido um dos países fortemente dependentes de empréstimos chineses para seu desenvolvimento, escreveu para o Financial Times alertando que, ao aceitar a China, a África está "se abrindo para uma nova forma de imperialismo". Ele também especificou que "a China adquire de nós bens primários e nos vende bens manufaturados. Isso era também a essência do colonialismo" (SANUSI, 2013).

A crescente dominância da China tem sido posta à prova pela repercussão que gerou tanto na Ásia quanto na África. O mesmo se aplica à América Latina, que é mais rica e politicamente mais forte que a África, e é geograficamente mais longe da China do que a Ásia. Um exemplo é o crescimento da aliança entre Estados Unidos e Brasil, um dos beneficiados pela bonança gerada pela demanda chinesa, como visto em seções anteriores, ao reclamar da China na OMC, por causa de suas políticas comerciais e cambiais. A limitação da influência política da China em outros países restringe, em última instância, a expansão da influência econômica do país.

Uma solução tentada pela China em resposta a tal repercussão foi a construção de instituições multilaterais para mediar a expansão da economia chinesa em outros países em desenvolvimento ao lado dos empréstimos bilaterais e ajuda ao desenvolvimento que vinham prevalecendo até então. A criação do Banco Asiático de Investimento e Infraestrutura (AIIB), na primavera de 2015, visando ao financiamento de projetos de infraestrutura na Ásia central, sudeste asiático e sul da Ásia, é uma manifestação dessa tentativa. Muitos veem o AIIB como um aprofundamento do poder chinês na Ásia e no mundo em desenvolvimento. Entretanto, na realidade, trata-se 
de um passo atrás em relação à estratégia anterior de expansão econômica bilateral agressiva.

De acordo com um relatório da RAND Corporation, publicado em 2013, o montante anual de empréstimos e doações da China a outros países em desenvolvimento disparou entre 2001 e 2011, e o montante acumulado ao final desse período chegou a US\$ 671 bilhões, e esse valor deve ser muito maior hoje. Muitos desses empréstimos e doações vêm com condicionalidades que obrigam os receptores a contratarem empresas chinesas para os projetos ou adquirirem produtos feitos na China. Em comparação, a capitalização do AIIB pode chegar a US\$ 100 bilhões com a contribuição chinesa de US\$ 50 bilhões. Em 2014, a China também contribuiu com US\$ 40 bilhões ao novo Banco de Desenvolvimento dos BRICS, sediado em Xangai, colocando-se como um desafio para a liderança dos Estados Unidos no financiamento do desenvolvimento. As contribuições da China a esses novos bancos são consideravelmente pequenas em relação aos seus compromissos bilaterais. Na prática, a assistência bilateral chinesa funciona bem, e nesse sentido não haveria necessidade de tentar construir novos bancos multilaterais. A China certamente possui a capacidade de emprestar sozinha e, nesses casos, ela tem controle total sobre os termos do empréstimo e a quem será destinado. Em vez disso, a China decidiu que será limitada pelas outras partes interessadas no AIIB e no Banco dos BRICS de um jeito ou de outro, ainda que domine essas instituições, como seu principal credor.

O esforço da China em construir bancos multilaterais expressa um novo experimento no qual o país sacrifica parte de seu poder para ter o apoio e a legitimidade que os outros países participantes podem prover. $O$ interesse recém-descoberto da China por construir bancos multilaterais indica que ela pode estar se tornando menos dominante, não mais, no financiamento internacional para o desenvolvimento. É um pequeno passo para trás na onda chinesa de empréstimos bilaterais para o mundo em desenvolvimento na última década. Olhando para a história, foi a assistência econômica bilateral, mais do que a participação em instituições multilaterais, como o Banco Mundial, crucial para a ascensão dos Estados Unidos como a superpotência global em meados do século XX. O Banco Mundial foi criado em 1944 para financiar a reconstrução do pós-guerra; porém, assim que os Estados Unidos iniciaram o Plano Marshall e outros programas de assistência bilaterais em diferentes partes do mundo em meio à Guerra Fria, ele foi imediatamente colocado de lado, ofuscado por décadas, até ser revitalizado na década de 1970, quando o poder global dos Estados Unidos se enfraqueceu.

Além de moderar o avanço de sua economia por meio do experimento de construção de instituições multilaterais, Pequim tentou outra solução como resposta à repercussão contra a expansão da influência de sua economia, que foi projetar o hard 
power chinês. Isso significa seguir os passos de uma potência imperial tradicional, apoiando-se na extensão ultramarina do seu poder político e militar para subjugar qualquer oposição à expansão do seu poder econômico. O Livro Branco da Defesa Nacional da China, de 2013, diz explicitamente que proteger os interesses econômicos ultramarinos é agora um dos objetivos principais do Exército de Libertação Popular:

Com a integração gradual da economia chinesa ao sistema econômico mundial, os interesses ultramarinos se tornaram um componente integral dos interesses nacionais chineses. Questões de segurança têm proeminência crescente, envolvendo energia e recursos marítimos, rotas de comunicação marítima estratégicas, e pessoas jurídicas e cidadãos no exterior. (THE PEOPLE'S REPUBLIC OF CHINA, 2013, tradução nossa)

Não há dúvidas de que o exército chinês ainda não está pronto para a implantação de tropas no exterior a exemplo dos fuzileiros navais estadunidenses, embora cidadãos chineses tenham se tornado alvo "número um" em sequestros por terroristas e grupos rebeldes na África e as instalações chinesas tenham se tornado alvos valiosos para sabotagem (NYA INTERNATIONAL, 2015; ENR, 2014). Como reação, Pequim alistou um dos mais brutais mercenários internacionais para defender seus interesses na África. Em 2014, Erik Prince, fundador e antigo CEO da empresa de segurança Blackwater, fortemente envolvida na segunda invasão dos Estados Unidos ao Iraque, foi recrutado para se tornar o presidente de uma firma de logística e gerenciamento de risco em Hong Kong. A empresa, chamada Frontier Services Group, tem laços estreitos e um conselho diretor cruzado com o maior conglomerado estatal chinês, CITIC. Seu principal negócio é prover serviços de segurança a companhias chinesas na África (HUNG, 2015, p. 141-142).

A manifestação do interesse chinês em projetar seu hard power no exterior está em linha com a trajetória de desenvolvimento das primeiras potências capitalistas. Como Lenin observou em seu livro O Imperialismo, Etapa Superior do Capitalismo, a necessidade de exportar capital para o exterior leva inevitavelmente os Estados a projetarem seus poderes político e militar externamente para proteger o circuito de acumulação do capital exportado, levando à expansão imperialista e à rivalidade interimperialista com outras potências exportadoras de capital. A expansão do poder geopolítico da China no Sul Global e na Ásia em particular tem alarmado os Estados Unidos, que lançou a política do "pivô asiático" em 2012 para reforçar sua presença geopolítica e militar na Ásia e fortalecer sua cooperação com os vizinhos da China, na tentativa de contrabalancear a influência chinesa crescente. Esses acontecimentos podem levar à rivalidade interimperialista clássica entre a China e os Estados Unidos. Outras 
potências ascendentes, como a Índia, também estavam cautelosas com a expansão da influência chinesa em países dentro da sua tradicional esfera de influência, como Nepal e Sri Lanka, nesse caso, compreensivelmente levando a uma tensão crescente entre os dois gigantes.

Entretanto, por ora, a China está longe de ser a nova potência dominante ou hegemônica do mundo, mesmo que sua presença crescente pelo mundo em desenvolvimento já esteja alterando a dinâmica da política global ao empoderar outros países em desenvolvimento. Como muitos estudos apontam (KENTOR e BOSWELL, 2003), a subordinação dos países em desenvolvimento aos países desenvolvidos ocidentais não foi causada pelo comércio ou investimento dos países desenvolvidos per se, mas foi resultado do papel monopolista que os países desenvolvidos do Ocidente assumiram como fontes de investimento e como parceiros comerciais majoritários. Com uma ampla gama de países em desenvolvimento competindo por investimento de um número limitado de países desenvolvidos ou exportando produtos similares de baixo valor agregado a um número limitado de países desenvolvidos, os países em desenvolvimento, particularmente os exportadores de commodities, possuem baixo poder de barganha. Essa falta de poder de barganha torna esses países menos capacitados para resistir às demandas dos países desenvolvidos em arranjos bilaterais ou organizações multilaterais, como a OMC. Com a prevalência da China como parceiro comercial e fonte de investimento alternativo às tradicionais potências ocidentais, os países em desenvolvimento começam a reduzir sua anterior dependência unilateral do Ocidente para investimento e mercados. Isso melhora sua posição de barganha em negociações bilaterais e multilaterais. Assim sendo, o crescimento da influência chinesa na política global encontra entusiastas no Sul Global, apesar das características imperialistas do seu poder. Isso é comparável às dinâmicas que proporcionaram à Alemanha alguma popularidade entre nacionalistas que procuravam independência do pacto colonial britânico no início do século XX.

A ascensão do G-20 como um bloco de negociações dos países em desenvolvimento na OMC é ilustrativa. O grupo foi iniciado por Brasil, África do Sul e Índia na reunião ministerial em Cancún, em 2003, com a intenção de conceber posições coletivas nas negociações com os países desenvolvidos em vários assuntos-chave. Eles resistiram coletivamente às demandas dos países desenvolvidos por maior abertura dos mercados financeiros e pela abertura de seus mercados agrícolas (HOPEWELL, 2012). A inclusão da China no grupo deu um grande impulso na participação do grupo no mercado mundial - uma vez que o PIB da China ultrapassou 10\% do PIB mundial e continua crescendo, ela é agora a maior economia do grupo. Embora a China não fosse ativa na organização e na elaboração de estratégias do G-20, posição ocupada por outros membros, como o Brasil, sua participação aumentou significativamente o 
poder do grupo. $\mathrm{Na}$ atual rodada de negociações de Doha sobre comércio, começada em 2001, a insistência do grupo pela redução drástica dos subsídios à agricultura em países ricos em troca de maior abertura levou a rodada de negociações sobre comércio a um impasse e quase a um colapso. Desde 2013 as perspectivas para a rodada de negociações de Doha continuam sombrias. Esse episódio sinaliza que a OMC não é mais a ferramenta da qual os países ricos podem se utilizar como desejarem para abrir os mercados dos países em desenvolvimento enquanto protegem seus próprios mercados. Isso mostra como a ascensão da China tem ajudado a sacudir a balança de poder entre os países ricos e os países em desenvolvimento, em favor dos últimos, apesar de a China não ter sido ainda capaz de desafiar diretamente grandes potências ocidentais na política global.

\section{CONCLUSÃO}

Muitos veem o milagre da economia chinesa como a materialização de um modelo alternativo de desenvolvimento à ortodoxia neoliberal promovida por Washington. Muitos também assumem que o crescimento do envolvimento político e econômico da China no Sul Global, particularmente nos seus países vizinhos na Ásia, está criando uma nova ordem geopolítica que desafia a dominação americana. Neste artigo viuse que o boom da China, movido fundamentalmente por um crescimento orientado para as exportações, é na realidade uma parte constitutiva da ordem global neoliberal, que foi criada por um núcleo de países nos anos 1980 como uma maneira de resolver suas crises capitalistas apaziguando o trabalho organizado através da realocação da produção para países com baixos salários. A China se utilizou da vantagem de seu remodelamento no capitalismo global para se tornar a fábrica do mundo ao explorar seu legado maoísta, que a deixou com uma vasta mão de obra rural com altas taxas de alfabetização e saúde de qualidade.

Quando o crescimento orientado para as exportações da China atingiu o seu limite, especialmente após a crise financeira global de 2008, o país se tornou mais dependente de investimentos em ativos fixos financiados por dívidas, o que impulsionou seu crescimento de curto prazo, mas agravou a sobrecapacidade e o endividamento da economia. A turbulência no mercado de ações, a aceleração da fuga de capitais e a desvalorização da moeda no verão de 2015 são apenas os mais recentes sinais de que a China está se movendo na direção de uma crise de superacumulação caracterizada pela queda da taxa de juros e instabilidade financeira. Tal crise tem sido moldada há algum tempo e tem pressionado a China a exportar seu excedente de capital na forma de ajuda externa, concessão de empréstimos e investimento estrangeiro direto para 
seus vizinhos asiáticos e outros países em desenvolvimento na África e América do Sul. A criação Banco de Investimento e Infraestrutura Asiático e a inauguração da iniciativa de construção de infraestrutura “One Belt, One Road" se expandindo para a Ásia central e para o Oceano Índico são as consequências dessa necessidade de exportar capital.

A ascensão chinesa como exportadora de capital está fazendo com que ela siga os passos das potências capitalistas-imperialistas precedentes, de projetar sua influência política externamente. Isso cria uma crescente inquietação entre os países vizinhos sobre a dominação regional da China e também coloca o país em rota de colisão com os Estados Unidos, que ainda dominam a ordem de segurança política existente na Ásia-Pacífico, precipitando uma nova competição interimperial. A tensão crescente no Mar do Sul da China é um exemplo disso. Assim sendo, a ascensão chinesa traz efeitos contraditórios no status quo político-econômico global, hoje centrado nos Estados Unidos. Por um lado, ela ajuda a reproduzir o status quo ao perpetuar a ordem global neoliberal baseada no livre comércio, mobilidade do capital industrial e na destruição do poder de barganha do trabalho. Por outro lado, ela apresenta novos desafios à dominação geopolítica ocidental na Ásia e em outras partes do mundo. Se tais acontecimentos irão levar a uma dominação renovada do mundo pelo Ocidente, intensificando conflitos globais e regionais, ou a uma ordem global mais igualitária, ainda estamos longe de determinar. Em qual direção o mundo irá embarcar vai depender consideravelmente das lutas políticas e dos conflitos entre diferentes forças políticas e sociais dentro da China e de como esses conflitos estarão conectados aos mesmos conflitos em outras partes do mundo.

\section{REFERÊNCIAS BIBLIOGRÁFICAS}

BOND, P. Sub-imperialism as lubricant of neoliberalism: South African 'deputy sheriff' duty within BRICS. Third World Quarterly, v. 34, n. 2, p. 251-270, 2013.

BOWER, E. Z. China's activities in Southeast Asia and implications for US interest. Statement before the US-China Economic and Security Review Commission. 2010. Disponível em: $<$ https://csis.org/files/100204_bower_testimony.pdf >.

BRAUTIGAM, D. The Dragon's Gift: the real story of China in Africa. New York: Oxford University Press, 2011.

ENR - ENGINEERING NEWS RECORD. Pushback against Chinese workers escalates in Africa. Engineering News Record, 14 out. 2014. Disponível em: <http://www.enr.com/articles/3029-pushback-against-chinese-workers-escalates-in-africa?v=preview $>$.

GALLAGHER, K.; PORZEGANSKI, R.The Dragon in the Room: China and the Future of Latin American industrialization. Stanford: Stanford University Press, 2010. 
GRIMSDITCH, M. China's investments in hydropower in the Mekong Region: The Kamchay Hydropower Dam, Kampot, Cambodia. Washington, D.C.: Bank Information Center, 2012. Disponível em: <http://www.bicusa.org/wp-content/uploads/2013/02/Case+Study+-+Chi na+Investments+in+Cambodia+FINAL+2.pdf $>$.

HAGLUND, D. In it for the long term? Governance and learning among Chinese investors in Zambia's copper sector. The China Quarterly, v. 199, p. 627-46, 2009.

HAMASHITA, T. China, East Asia, and the World Economy: regional and historical perspectives. New York: Routledge, 2008.

HOPEWELL, K. Shifting power in global economic governance: The Rise of Brazil, India and China at the WTO. Tese (Ph.D) - Departamento de Sociologia, Universidade de Michigan, 2012.

HOWE, C. The origins of Japanese trade supremacy: development and technology in Asia from 1540 to the Pacific War. Chicago: Chicago University Press, 1996.

HUNG, H. The China boom: why China will not rule the world. New York: Columbia University Press, 2015.

KANG, D. C. East Asia before the West: five centuries of trade and tribute. New York: Columbia University Press, 2010.

KARL, T. L. The paradox of plenty: oil booms and petro-states. Berkeley: University of California Press, 1997.

KENTOR, J.; BOSWELL, T. Foreign Capital dependence and development: a new direction. American Sociological Review, v. 68, n. 2, p. 301-13, 2003.

KRAUSE, L. The economics and politics of the Asian financial crisis of 1997-98. New York: Council on Foreign Relations, 1998.

LEE, C. K. Raw encounters: Chinese managers, African workers and the politics of casualization in Africa's Chinese enclaves. The China Quarterly, v. 199, p. 647-666, 2009.

LUM, T.; FISCHER, H.; GOMEZ-GRANGER, J.; LELAND, A. China's foreign aid activities in Africa, Latin America, and Southeast Asia. Congressional Research Service Report for Congress, 25 Feb. 2009. Disponível em: <http://www.fas.org/sgp/crs/row/R40361.pdf>.

NYA INTERNATIONAL. Kidnapping risk to Chinese nationals. Global Kidnap for Ransom Update, Apr. 2015. Disponível em: <http://www.nyainternational.com/sites/default/files/ no-index/NYA-Global-Kidnap-for-Ransom-Update-April-2015-362.pdf>.

O'CONNER, J. State building, infrastructure development and Chinese energy projects in Myanmar. Irasec's Discussion Papers, n. 10, 2011. Disponível em: <www.irasec.com>.

REILLY, J. China's unilateral sanctions. The Washington Quarterly, v. 35, n. 4, 2012.

ROACHE, S. K. China's impact on world commodity market. IMF Working Paper, n. 12115, 2012. Disponível em: <http://www.imf.org/external/pubs/ft/wp/2012/wp12115.pdf >.

SACHS, J. D.; WARNER, A. M. Natural resource abundance and economic Growth. Development Discussion Paper, Harvard Institute for International Development, n. 517a, 1995.

SANUSI, L. Africa must get real about Chinese ties. Financial Times, 11 mar. 2013. 
SHAFER, M. D. Winners and losers: how sectors shape the developmental prospects of states. Ithaca, N.Y.: Cornell University Press, 1994.

THE PEOPLE'S REPUBLIC OF CHINA. White Paper: the diversified employment of China's Armed Forces. Beijing: Information Office of the State Council, The People's Republic of China, 2012. Disponível em: <http://eng.mod.gov.cn/Database/WhitePapers/2012.htm> 